\title{
Survey of Relationship between Personality Traits with Mental Health and Academic Staffs' Job Satisfaction in the University of Guilan, Iran
}

\author{
Abbas Sadeghi', Mahboubeh Hosein Zadeh ${ }^{2}$, Gholam Hossein Niayfar ${ }^{3}$, Setareh Azizi ${ }^{4}$ \\ ${ }^{1}$ Department of Counselling, University of Guilan, Rasht, Iran \\ ${ }^{2}$ Department of Professional Health, Rasht, Iran \\ ${ }^{3}$ Department of General Psychology, Rasht, Iran \\ ${ }^{4}$ Department of Clinical Psychology, Rasht, Iran \\ Email: asadeghi1394@gmail.com, Niayfar67@gmail.com, setarehazizi@gmail.com
}

Received 21 June 2016; accepted 22 August 2016; published 25 August 2016

Copyright (C) 2016 by authors and Scientific Research Publishing Inc.

This work is licensed under the Creative Commons Attribution-NonCommercial International License (CC

BY-NC).

http://creativecommons.org/licenses/by-nc/4.0/

(c) (i) (9) Open Access

\begin{abstract}
The main aim of the research is survey of relationship between personality characteristics with academic staffs' job satisfaction and mental health in the University of Guilan. The statistic population was all these academic staffs in the year of 2014 (500). 196 individuals have selected by Kerjecy \& Morgan (1970) and random sampling method. The research instruments were personality characteristics (NEO), General Health Questionnaire (GHQ) and self-made questionnaires. Pearson's Correlation, Multiple Regression and Multiple Variant (Manova) have used for analyzing data. Results showed that there was a relationship among neurotic and settlement's personality characteristics with job satisfaction and neurotic, openness, extroversion personality characteristics and settlement with mental health. Some of personality characteristics had been anticipators of mental health and job satisfaction and personality characteristics with mental health and job satisfaction had differenced depend on sociologic variances relationships.
\end{abstract}

\section{Keywords}

Job Satisfaction, Mental Health, Personality Characteristics, Academic Staff

\section{Introduction}

Today, the issue of mental health, behavioral and social scientists was deeply concerned. Mental health helps 
people to create the right psychological methods compatible with the environment and more favorable solutions can choose to solve problems, such as stress, if constantly threatened person, man joyful, strong and able to carry out its social responsibilities (Banaian et al., 2008) [1]. Recently, research has been conducted linking personality traits and mental health. The results Jafarnejad et al. (2005) [2] showed negative correlations traits of neuroticism and extroversion, open-mindedness and positive relationship with mental health and the five personality factors involved in mental health prediction. Gross Carpet and Sufis (2006) [3] showed that personality dimensions extraversion, conscience, public health and there is a significant negative relationship. The results of logistic regression model showed that the three features five personality factors of neuroticism, extraversion and agreeableness were used and these characteristics could explain about 50 percent of the variance in general health. The findings were part Roodsari, Peyrovi and Abedian (2006) [4], showed that life satisfaction and social support significantly predict mental health. Researchers Obtained evidence that there was a relation between health and character in which individuals that anxious, depressed and violent were more prone to diseases (Friedman and Butkivly, 1987) [5].

Costa and McCrae (1986) [6] found that happiness nervousness associated with high levels of extraversion and low levels respectively. Most of the other preceding studies such as Chu Chen (2000) [7], confirmed this relationship-limitations. The findings showed that 32 to 56 percent of the variance in personality can predict and explain mental health scores (Razaviyeh et al., 2011) [8].

Geoffrey et al. (2015) [9] resulted that the lack of high quality evidence about the attitude about the mental health of people with a diagnosis of borderline personality disorder there. This is an important gap in the attitudes of professions poor nurses have involved in the care of this group. More research is needed to determine the elements of an effective training program.

\section{Hypotheses}

1) There is a relationship personality characteristics and job satisfaction of academic staff members.

2) There is a relationship between personality traits and mental health academic staff members.

3) There is a relationship mental health and job satisfaction among academic staff members.

4) Explaining the five factor Personality significant share of job satisfaction among academic staff members.

5) Explaining the five factor personality significant share of mental health academic staff members.

\section{Methodology}

The research method in this study is correlational, such as its purpose, in addition to examining the relationship between personality traits, job satisfaction and mental health, personality traits and variables of job satisfaction on mental health.

\section{Population}

The population of this research includes all the academic staff members of the University of Guilan in 1393 that approximately 500 .

\section{Sampling}

The present study sample consisted of 196 academic staff members of Guilan University in 1387 with stratified sampling method with the use of the Chris and Morgan (1970), were selected.

Tables 1-4 respectively for demographic variables gender, age, academic Rank and Faculty Set the frequency and cumulative percentage obtained in a separate table to four specified.

\section{Research Instruments}

\subsection{Scale Characteristics}

NEO-PI-R (long form) The questionnaire includes 240 questions that include mental nervousness 5 major scale, flexibility, extraversion, agreeableness and conscientiousness. Scales between 0.81 to 0.99 and Cronbach's alpha coefficient for retest results showed a correlation coefficient of reliability test of 0.55 to 0.78 for Maccarry and Costa respectively. The first questionnaire by Maccarry and Costa built in 1970 and in 1991 was re-examined. Compliance Persian translation of the test was started in 1376 (Haghshenas 2007) [10]. 
Table 1. The prevalence of gender-related academic staff members of the University of Guilan.

\begin{tabular}{ccccc}
\hline & & Number & Percentage & $\begin{array}{c}\text { Cumulative } \\
\text { percentage }\end{array}$ \\
\hline \multirow{3}{*}{ Gender } & Male & 173 & 88 & 88 \\
& Female & 21 & 11 & 99 \\
& Not Declared & 2 & 1 & 100 \\
& Total & 196 & 100 & \\
\hline
\end{tabular}

Table 2. The prevalence of age-related academic staff members of the University of Guilan.

\begin{tabular}{ccccc}
\hline & Number & Percentage & $\begin{array}{c}\text { Cumulative } \\
\text { percentage }\end{array}$ \\
\hline Age & $25-30$ & 11 & 6 & 6 \\
& $31-35$ & 32 & 19 & 25 \\
& $36-40$ & 40 & 24 & 49 \\
& $41-45$ & 35 & 21 & 70 \\
\hline
\end{tabular}

Table 3. The prevalence of Science ranking-related academic staff members of the University of Guilan.

\begin{tabular}{ccccc}
\hline & & Number & Percentage & $\begin{array}{c}\text { Cumulative } \\
\text { percentage }\end{array}$ \\
\hline \multirow{2}{*}{ Academic Instructor Training } & 3 & 2 & 2 \\
trainer & 23 & 14 & 16 \\
Science & Assistant Professor & 118 & 70 & 96 \\
& Associate Professor & 19 & 11 & 100 \\
& Professor & 6 & 3 & 97 \\
\hline
\end{tabular}

Table 4. The prevalence of faculty-related academic staff members of the University of Guilan.

\begin{tabular}{cccc}
\hline & Number & Percentage & $\begin{array}{c}\text { Cumulative } \\
\text { percentage }\end{array}$ \\
Humanity & 48 & 28 & 28 \\
Agriculture & 36 & 21 & 49 \\
Technical & 41 & 24 & 73 \\
Basic & 26 & 16 & 99 \\
Faculty & 10 & 6 & 100 \\
Natural resources & 8 & 5 & 95 \\
Physical Education & 196 & 100 & \\
\hline
\end{tabular}




\subsection{General Health Questionnaire (GHQ)}

First was used by Goldberg General Health Questionnaire (1972). The main form of short form with 60 questions from 12 to 28 questions are also prepared and translated in 38 languages on its psychometric studies have been conducted in 70 countries. Test a person's symptoms one month before the test until the time of evaluation (self-evaluation) great negative. This version is consistent with the analytical factors by Goldberg and Hiller (1979) was conducted, four fundamental factors include measures of physical symptoms, anxiety sleep disorder, depression, social dysfunction and a scale is extracted. Cronbach's alpha of the scale to $0.88-0.93$. They reported. Amman God (2004) also wrote Cronbach's alpha and the General Health Questionnaire 0.83 - 0.86. As they (Motamedi Shalamzary et al., 2002).

\subsection{Job Satisfaction}

The scale of job satisfaction in this study, job satisfaction is a self-made questionnaire with 20 questions. The validity of the questionnaire was pilot in Alpha $81 \%$ accepted and validity by three teachers and faculty of psychology and counseling about Tide is located.

\section{Results}

First hypothesis: there is a relationship between personality traits and job satisfaction of faculty members.

Due to the lack of theoretical basics for overall score personality traits using a questionnaire (NEO), in this section, the results of correlation coefficient (r Pearson) performed between each of the personality traits and job satisfaction in sample group. The results of the correlation coefficient mentioned in Tables 4-7 is presented.

As reported in Table 5, the results of Pearson correlation coefficient indicates nervousness and negative relationship between job satisfaction and positive relationship between job satisfaction and agreement at a significance level $(\mathrm{P}<0.05)$ respectively. The traits of extraversion, open-mindedness and conscientiousness with job satisfaction not seen.

The second hypothesis: there is a relationship between personality traits and mental health academic staff members of the University of Guilan the results of Pearson correlation coefficient, is presented in Table 6.

As Table 6 shows, there is a negative correlation between extraversion data analysis indicates a significant level $(\mathrm{P}<0.01)$ and agreed on a level of significance $(\mathrm{P}<0.05)$ and direct and positive relationship between nervousness general health, open-mindedness and mental health at a significance level $(\mathrm{P}<0.01)$ respectively. Features a significant relationship between conscience and mental health is not seen. It should be noted that high scores indicate high levels of public health morbid symptoms such as depression, somatic symptoms, and anxiety

Table 5. Shows the results of the Pearson correlation coefficient between the five personality factors and job satisfaction among academic staff members of the University of Guilan.

\begin{tabular}{cccccccc}
\hline & & $\mathrm{N}$ & $\mathrm{E}$ & $\mathrm{O}$ & $\mathrm{A}$ & $\mathrm{C}$ \\
\hline \multirow{3}{*}{ Job satisfaction } & $\mathrm{r}$ & $0.259^{* *}$ & 0.047 & -0.030 & $0.199^{*}$ & 0.079 \\
& Significance level & 0.000 & 0.431 & 0.0623 & 0.001 & 0.191 \\
& Number & 196 & 196 & 196 & 196 & 196 \\
\hline
\end{tabular}

** Significance level.

Table 6. Results of Pearson correlation coefficients between the five factors of personality and mental health in academic staff members of the University of Guilan.

\begin{tabular}{|c|c|c|c|c|c|c|}
\hline & & $\mathrm{N}$ & $\mathrm{E}$ & $\mathrm{O}$ & A & $\mathrm{C}$ \\
\hline & $r$ & $0.401^{* *}$ & $-0.391^{* *}$ & $0.163^{* *}$ & $-0.127^{*}$ & -0.113 \\
\hline \multirow[t]{2}{*}{ Mental health } & Significance level & 0.000 & 0.000 & 0.006 & 0.034 & 0.06 \\
\hline & Number & 196 & 196 & 196 & 196 & 196 \\
\hline
\end{tabular}

\footnotetext{
${ }^{* *}$ Significance level.
} 
Table 7. Pearson correlation coefficient between the Job satisfaction and public health faculty.

\begin{tabular}{cccc}
\hline & $\mathrm{r}$ & $-0.358^{* *}$ & \\
General health & Significance level & 0.000 & Job satisfaction \\
& Number & 196 & \\
\hline
\end{tabular}

${ }^{* *}$ Significance level.

Table 8. Multiple regression analysis related to five personality factors and job satisfaction in the sample.

\begin{tabular}{cccccc}
\hline Source of variation & Sum of squares & Degrees of freedom & Mean squares & F & Mean \\
\hline Regression & $11,159.571$ & 5 & 2231.914 & 5.719 & 0.00 \\
Remaining & $106,145.321$ & 169 & 390.24 & & \\
\hline
\end{tabular}

Table 9. Results of the multivariate regression.

\begin{tabular}{ccccccc}
\hline Variable & Index & B & SEB & Beta & T & Significant level \\
\hline & N & -0.967 & 0.241 & -0.291 & -4.01 & 0.000 \\
Personality & E & -0.566 & 0.242 & -0.169 & -2.34 & 0.02 \\
& O & -0.285 & 0.337 & -0.05 & -0.845 & 0.4 \\
& A & 0.501 & 0.3 & 0.123 & 1.67 & 0.096 \\
\hline
\end{tabular}

symptoms and sleep disorders. As well as poor social functioning so high nervousness and open-mindedness with high pathological symptoms related to mental health and high extraversion traits and deal with the symptoms linked to low.

The third hypothesis: there is a relationship between mental health and job satisfaction among academic staff members of the University of Guilan Pearson correlation coefficient was used to investigate the above hypothesis that the results are presented in Tables 4-9 in throughput.

The correlation coefficient between job satisfaction and general health significance level $(\mathrm{P}<0.01)$ is the meaningful. In other words can say with 99\% confidence there is an inverse relationship between mental health and job satisfaction means increased job satisfaction, general health (mental health symptoms) decreases. The fourth hypothesis: five personality factors contributing to job satisfaction of faculty members. In this section, the results of multiple regression done, between five personality factors and job satisfaction results in Table 8 and Table 9 in the sample MyPrdazym.kh reflected.

Table 8 shows the $\mathrm{F}$ observed that due to regression analysis, compared with the critical values, meaning Democrats. Because it can be a linear combination said Components in relation to job satisfaction. The values of the $R(0.308), R^{2}(0.095)$, also have been identified. The $R^{2}$, revealed that nearly 10 percent of the variance in job satisfaction by a linear combination of five factors of personality (neuroticism, extroversion, open-mindedness, agreeableness, and conscientiousness) explained in throughput.

According to Table $9 \mathrm{~s}$ the scatter plot and regression line Betas are different to the Beta, show that change a unit on the SD N, E, O, A, C can score or job satisfaction respectively $-0.291,-0.169,-0.05,0.123,0.022$ change. Therefore beta coefficients specified in throughput among personality traits, respectively, nervousness (29\% negative) and extraversion (17\% negative) can better predict job satisfaction.

Fifth hypothesis: five personality factors explain a significant share of the mental health faculty.

In this section, the results of multiple Regressions done, the five factors of personality and mental health of the sample. The results of which are reflected in Table 10 and Table 11.

According to Table 9, the F observed that due to regression analysis, compared with the critical values, 
Table 10. Multiple regression analysis of five factors of personality and general health of the sample group.

\begin{tabular}{cccccc}
\hline Source of variation & Sum of squares & Degrees of freedom & Mean squares & F & Significant level \\
\hline Regression & $15,198.74$ & 5 & 3039.75 & 19.435 & 0.00 \\
Remaining & $42,542.55$ & 191 & 156.41 & & \\
\hline
\end{tabular}

Table 11. Results of the multivariate Regression.

\begin{tabular}{ccccccc}
\hline Variable & Index & B & SEB & Beta & T & Significant level \\
\hline & N & 0.856 & 0.152 & 0.367 & 5.61 & 0.000 \\
Personality & E & -0.631 & 0.153 & -0.268 & -4.11 & 0.000 \\
factor & O & 0.831 & 0.213 & 0.208 & 3.9 & 0.000 \\
& A & 0.552 & 0.19 & 0.193 & 2.9 & 0.004 \\
& C & -0.048 & 0.173 & -0.017 & -0.28 & 0.78 \\
\hline
\end{tabular}

meaning Democrats. Because basics can say in relation to mental health. Numbers a linear combination of $\mathrm{R}$ (0.513), $R^{2}(0.263)$, also have been identified. The $R^{2}$, revealed that nearly $26 \%$ of general health variance by a linear combination of five factors of personality (neuroticism, extroversion, open-mindedness, agreeableness, and conscientiousness) is explained.

As Table 11 shows the different betas. Due to the Beta, shows, change a unit on the SD N, E, O, A, C can score or mental health status in the order of $0.367,0.268,-0.268,0.193,-0.017$ change. Therefore beta coefficients specified in throughput among personality traits, respectively, nervousness (37 percent), extraversion (27\% negative), open-mindedness (21\%) and consensus (12\%) than My can predict mental health faculty.

\section{Discussion}

The relationship between personality traits and job satisfaction and job satisfaction nervousness. It was concluded that the negative relationship between agreeableness and marital satisfaction, there is a direct correlation. The traits of extraversion, conscientiousness open-mindedness and there was no significant relationship with job satisfaction. The other preceding studies, showed conflicting results including, Razavieh et al., (2011) [8]. Shafiee et al. (2011) [11] stated that the relationship between personality traits of neuroticism and general health of heart and kidney disease and normal subjects were significantly different. There are, however, between personality traits of extraversion, openness, responsibility and agreeableness public health. There is no significant difference in disease and normal subjects that the following research to research in the field of communication features nervousness and job satisfaction, consistent and open-mindedness and communication features are unequal job satisfaction because in the present study between open-mindedness and job satisfaction was shown. Characteristics of introversion, conscientiousness arm thinking, positive relationship with job satisfaction when the staff there will be understood by the managers and upgraded. Otherwise, if one side of these characteristics, job conflicts exist or mental health in jeopardy (Mohammad Zadeh et al., 2009) [12]. Ilies \& Judge (2002) [13], a study of 27 patients conducted of staff in a period of four weeks; they found that job satisfaction and mental states to each other are dependent personality; mental state affects your job satisfaction. Since that job dissatisfaction in hand in subjects with severe personality traits administrators subjects in the study, interpretation it helped a lot. The subject of the present study was to constraints. In contrast to the orientation of agreement or compatibility features than others, including traits such as type of friendship, trust and humility respectively. People with these characteristics have high power compatibility and in case of non-cooperation wife also capable of many responsibilities done in your life with a positive attitude and no hostile intentions and try virgin and behaviors of others, and in the see life. Compatibility psychological point of view, is the process different patterns answering to environmental changes. Important aspect of compatibility with the issue of marriage, life satisfaction (Razaviyeh et al., 2011) [8]. Its first researches in the field of mental health and personality traits relevant to the investigation Costa and McCrae (1986) [6], which suggests a positive relationship is the inverse 
correlation characteristics of extraversion and happiness and nervousness Chen et al. (2000) [7] confirmed this results (Razaviyeh et al., 2011) [8]. In a study of Lu et al. (2007) [14] showed that job satisfaction, concerns itself have adverse effects on stress, which means that takes whatever job satisfaction, stress will be less. The results show that the higher health is public health staff will have higher job satisfaction. Jafarnejad et al. (2005) [2] concluded that the negative relationship between mental health and nervousness and there is a direct correlation between extraversion and mental health. The findings obtained in the present study, Sharma et al. (2010) [15]. The relationship between personality factors and general health factors indicated that educated young people between general health and neuroticism $(r=0.36)$, extraversion $(r=-0.25)$ correlation and between agreeableness and openness there is no public health. But the investigation Gross Carpet and Sufis (2006) [3], a negative correlation between extraversion and conscientiousness with mental health report is not in line with the findings. In the present study, there was no connection between consciousness and mental health. Study conscientiousness and positive relationship between mental health. It's about open-mindedness and mental health research only in Jafarnejad et al. (2005) [2] found that the type of relationship has been positive. This finding is consistent with the results of this study. In this study, there is a negative relationship between mental health and features open-mindedness. People with high nervousness in the face of problems and was not able to resiliency and emotional reactions show that, in fact, failing to control negative emotions such as anger and aggression are less able to solve problems in the form of problem-oriented use of style coping. On the other hand, people who had high neurosis Relief for depression, anxiety you were prone to physical and mental illness are more prepared for (Schultz, 2001) [16]. Explained positive relationship between open-mindedness and mental health could be argued perched probably those with high scores on open-mindedness towards outer experiences are curious about their new unconventional values are more fun. In other words imaginative life more active and shape to your imagination meditate on it and to use it to foster their creativity addressing. People with these characteristics are usually looking for excitement and pleasant thoughts in his imagination imagine life without limiting (Haghshenas et al., 2007) [10] is dumped. Usually with the hypothesis of extraversion, such as socialization and social abilities, like people, prefer large groups and gatherings, with assertiveness, active and talkative, energetic approach to the material world and social associations indicate that the person is. Social adaptability and prosaically orientation marker in front of a hostile attitude toward others is that features such as altruism, kindness, trust and humility to be included. It is natural that the person has these characteristics alone, however, negative thoughts, isolation and low self-esteem, symptoms of depression and hostility towards others who are in conflict with mental health, less is made and man the risk of physical diseases and immune disease symptoms built (Jafar Nejad et al., 2005) [2]. Next reconciliation between individual desires. Mental health and maintain harmonious relationships and compatibility for an undeniable necessity. And no interpersonal incompatibility can also be caused by psychological disorders illusion may lead to psychological problems. In the field of mental health and job satisfaction preceding studies correlate very accomplished and achieved mixed results. Some positive relationship between the two variers to research and reports including, trusting Wishman (2004) [17]. The result of the present study was to align with the findings. Baksheesh, AR and Mortazavi, M. (2010) [18] noted that there is no association between job satisfaction and general health. There is also the result of some research Ha causes job satisfaction gained in the relationship between general health. Study including USB et al. (1984) that social support with job satisfaction and effective in predicting mental health. Gross and Sufis (2006) [3] pointed out that mental health can be $50 \%$ by the characteristics of neuroticism, extraversion and agreeableness predicted.

\section{Conclusions}

The present study has limitations, including the fact that only the academic staff members at the University of Guilan have been focused. Given that the definitions Site definitions faculty research from variation are different. Thus, as one vacancy to interview and evaluate managers' questioners, our study highlighted flora. The faculty for generalization of the results is difficult to compare Ast.dm according to clinical and nonclinical groups in mental health and non-examine the changing role of groups, other limitations of the study.

It is recommended that during the study and treatment of psychiatric disorders, viewed from the employment, problems are related to the treatment of psychiatric disorders in a systematic strategies to improve treatment satisfaction and quality of the work environment should be considered in future investigations to determine the best ways to cure people with disorders on the promotion of job satisfaction pay anxiety and depression. 


\section{References}

[1] Shayesteh, P.N. and Haghighi, L. (2008) The Relationship between Mental Health and Marital Satisfaction of Married Women. Scientific Journal of Hamadan Nursing \& Midwifery, 2, 52-58.

[2] Jafarnejad, P., et al. (2005) Investigated the Relationship between the Five-Factor Model of Personality, Coping Styles and Mental Health in Undergraduates. Journal of Psychology and Educational Sciences, 51-74.

[3] Gross Carpet, M.T. and Sufis, H. (2006) Explore the Relation between Personality and General Health among Students of Tabriz University of Psychology and Education Studies. 63-47.

[4] Roodsari Payrovi, A., Compliance, H. and Abedian, A. (2006) The Relationship between Life Satisfaction and Social Support and Mental Health in College Students. Journal of Mental Health, 145-152.

[5] Friedman, H.S. and Booth-Kewley, S. (1987) The Disease-Prone Personality. American Psychologist, 42, 539-555. http://dx.doi.org/10.1037/0003-066X.42.6.539

[6] McCrae, R.R., Costa Jr., P.T. and Busch, C.M. (1986) Evaluating Comprehensiveness in Personality Systems: The California Q-Set and the Five-Factor Model. Journal of Personality, 54, 430-446. http://dx.doi.org/10.1111/j.1467-6494.1986.tb00403.x

[7] Chu Chen, Y. (2005) Study of the Relationship of Personality Traits and Job Satisfaction, among Professional Sales Representatives in the Pharmaceutical Industry in Taiwan. Context for Examining Celebrity Worship and Mental Health. British Journal of Psychology.

[8] Razavieh, A.L. and Bohlouli Asl, F. (2011) Personality Characteristics and Job Satisfaction Married Marital Veterans Affairs Shiraz Shahid Foundation. Journal of Scientific-New Research from the Community, 1-18.

[9] Dickens, G.L., Hallett, N. and Lamont, E. (2015) Interventions to Improve Mental Health Nurses’ Skills, Attitudes, and Knowledge Related to People with a Diagnosis of Borderline Personality Disorder: Systematic Review.

[10] Haghshenas, H., Chamani, A. and Firoozabadi, A. (2007) Comparison of Characteristics Mental Health of High School Students Gifted Ordinary High Schools. Journal of Mental Health, 57-66.

[11] Shafiei, H., Javidi, H. and Kazemi, S. (2011) Comparison between Personality Traits and Health Care in Women and Men with Heart and Kidney Disease. Quarterly Journal of Sociology of Women, 2, 149-162. (In Persian)

[12] Mohammad Zadeh, H. (2009) Survey of Personality Traits Influence Marital Satisfaction Damghan CITY. MA Thesis Psychology, Faculty of Education and Psychology, University of Tabriz.

[13] Ilies, R. and Judge, T.A. (2002) Understanding the Dynamic Relationship among Personality, Mood \& Jobsatisfaction: A Field Experience Sampling Study. Organizational Behavior and Human Decision Processes, 89, 1119-1139. http://dx.doi.org/10.1016/S0749-5978(02)00018-3

[14] Lu, K.Y., Chang, L.C. and Wu, H.L. (2007) Relationship between Professionals Commitment, Job Satisfaction, and Work Stress in Public Health Nurses in Taiwan. Journal of Professionals Nursing, 23, 110-116. http://dx.doi.org/10.1016/j.profnurs.2006.06.005

[15] Sharma, M., Kaveri, S.N. and Yadava, A. (2010) Personality Factors as Correlates of Health among Adults. Journal of the Indian Academy of Applied Psychology, 36, 328-333.

[16] Schultz, F.D. and Schultz, S.A.S. (2001) Theories Character. Syed Yahya Jamhidi More Tehran Edition.

[17] Whishman, M.A., Uebelacker, L.A. and Weinstocks, L.M. (2004) Psychopathology and Marital Satisfaction. Journal of Consulting and Clinical Psychology, 72, 830-838. http://dx.doi.org/10.1037/0022-006X.72.5.830

[18] Baksheesh, A.R. and Mortazavi, M. (2010). The Relationship between Sexual Satisfactions, Marital in Couples’ Public Health. Journal of Applied Psychology, 85-73. 


\section{Submit or recommend next manuscript to SCIRP and we will provide best service for you:}

Accepting pre-submission inquiries through Email, Facebook, LinkedIn, Twitter, etc.

A wide selection of journals (inclusive of 9 subjects, more than 200 journals)

Providing 24-hour high-quality service

User-friendly online submission system

Fair and swift peer-review system

Efficient typesetting and proofreading procedure

Display of the result of downloads and visits, as well as the number of cited articles

Maximum dissemination of your research work

Submit your manuscript at: http://papersubmission.scirp.org/ 